\title{
Frustration and the production of schedule-induced polydipsia
}

\author{
MICHAEL L. THOMKA \\ DePaul University', Chicago, Illinois 60614 \\ and \\ ROBERT A. ROSELLINI \\ University of Pennsylvania, Philadelphia, Pennsylvania 19174
}

\begin{abstract}
In two experiments, the hypothesis that frustration mediates the production of schedule-induced polydipsia was tested. In Experiment I, a group in which reward was reduced from 6 to 2 pellets of food in an operant chamber was found to increase water intake compared to a group maintained at 2 pellets reward. In Experiment II, rats trained to approach food on a partial reinforcement schedule in a runway subsequently showed lower levels of water intake in the operant test for polydipsia than rats given continuous reinforcement during runway training. The results are interpreted as supporting a frustration hypothesis of schedule-induced polydipsia and are discussed within the context of persistence theory.
\end{abstract}

Excessive water intake in a relatively short period of time is produced by the intermittent delivery of small amounts of food to a hungry animal (Falk, 1969, 1971). This phenomenon has been termed schedule-induced polydipsia (SIP). It is evident under a wide variety of body weights, schedules of reinforcement, and magnitudes of reinforcement (Falk, 1969; Freed \& Hymowitz, 1972). It has also been documented in a number of different species, such as the rat (Falk, 1961), mouse (Palfai, Kutscher, \& Symons, 1971), pigeon (Shanab \& Peterson, 1969), rhesus monkey (Schuster \& Woods, 1966), and man (Kachanoff, Leveilles, McClelland, and Wayner, 1973).

The nature of the procedures which produce SIP appear similar to those of a partial reinforcement paradigm which also produces frustration (Amsel, 1958). in either situation, approach responses to the food cup are only occasionally reinforced. Frustration should be produced in the typical SIP design since the number of pellets available to the animal at any one time is far less than the number of pellets a deprived animal will normally consume in a continuous meal (Lotter, Woods, \& Vaselli, 1973). The data showing that the level of SIP decreases with increasing meal size and with decreases in deprivation level (Falk, 1971) also suggest a frustration hypothesis of SIP, since both these manipulations should also decrease frustration.

Several authors have suggested a frustration interpretation of SIP (e.g., Denny \& Ratner, 1970; Kissileff, 1973; Palfai, Kutscher, \& Symons, 1971; Panksepp, Toates, \& Oatley, 1972). However, this formulation has

The present research was supported by State of Illinois Grant, Department of Mental Health No. 290-13-RD, to Thomas S. Brown, and NSF Traineeship Grant No. GZ-2350 to the second author. Reprint requests should be sent to Michael L. Thomka, Department of Psychology, DePaul University, 2219 N. Kenmore Ave., Chicago, Ilinois 60614 . not been clearly elaborated and has received no direct experimental attention. Amsel $(1958,1962)$ has proposed a well articulated theory of frustration. The present series of experiments was specifically aimed at testing the applicability of frustration theory to the SIP phenomenon.

Frustration theory suggests that when a rat is exposed to a fixed time (FT) feeding schedule, which delivers a substantially lower amount of food than would normally be consumed, primary frustration $\left(R_{f}\right)$ is produced. Primary frustration should then energize the next most probable response (cf. Amsel \& Roussel, 1952). In an SIP situation, then, primary frustration should energize drinking. Two characteristics of the SIP design seem to make drinking a very likely response. First, the normal feeding pattern of the rat is to eat and then drink (Lotter, Woods, \& Vaselli, 1973). Second, the positioning of the water spout in close proximity to the food cup would seem to make the spout a salient cue. The frustration hypothesis then predicts that procedures which increase primary frustration in the SIP situation should produce an increase in water intake.

Conversely, frustration theory also suggests a method whereby SIP should be reduced. Through partial reinforcement procedures, animals can be trained to persist in the face of frustration. Due to the intermittent introduction of primary frustration into the partial reinforcement situation the anticipatory frustration responses and stimuli $\left(\mathrm{I}_{\mathrm{f}}-\mathrm{s}_{\mathrm{f}}\right)$ become conditioned to approach to the goal where normally they would elicit avoidance. This theorizing predicts that, if animals are trained to approach food under partial reinforcement conditions, anticipatory frustration-produced stimuli should become conditioned to approach to food. When later tested in an SIP situation, these animals should show an attenuated level of water intake, since 


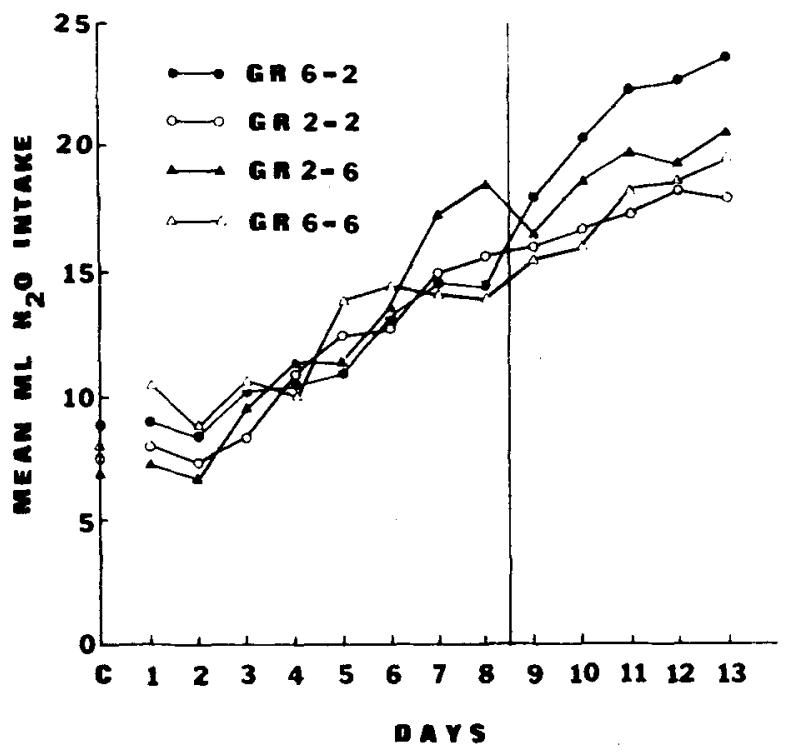

Figure 1. Mean water intake for the four treatment groups as a function of days of training (Days 1-8) and incentive shift test (Days 9-13).

anticipatory frustration encountered in the SIP situation should also be conditioned to continued goal approach. Thus lower levels of SIP should be obtained under these conditions, since continued approach to the goal should interfere with approach to the drinking spout.

\section{EXPERIMENT I}

The present experiment tests the prediction that manipulation of the level of primary frustration by introducing a shift in magnitude of incentive during the SIP procedure will affect the level of SIP. Rats were given either a high or low amount of reward on an SIP producing schedule and were subsequently shifted to the opposing level of reward. It was expected that rats that received the downward shift would show greater levels of SIP than controls maintained on the lower reward level throughout the SIP procedure.

\section{Method \\ Subjects. The subjects were 32 male Holtzmann rats approx- imately 100 days of age at the start of the experiment. They were housed in individual cages and had continuous access to water. Seven days prior to the start of the experiment, they were reduced to $85 \%$ of their free feeding body weight.}

Apparatus. Four operant chambers $(35.5 \times 30.5 \times 26.5 \mathrm{~cm})$ were used. The front and back walls of the chambers were constructed of aluminum and the sides of clear Plexiglas. A $31 \mathrm{x}$ $25 \times 13 \mathrm{~mm}$ foodcup was centered on the front wall, and a stainless steel drinking spout was $6.5 \mathrm{~cm}$ to the right of the foodcup. White masking noise was used in each chamber throughout the experiment.

Procedure. Prior to training (Day C), all animals were given $1 / 2 \mathrm{~h}$ free access to the number of pellets (either 180 or 60 ) they were to receive during polydipsia training. The water consumption on this control day was measured.
The 32 animals were assigned to the four treatment groups $(\mathrm{N}=8)$ so that all groups were approximately equal in mean body weight (range $317 \cdot 322 \mathrm{~g}$ ). Two of the four groups were given 8 days of polydipsia training with low reward $(245-\mathrm{mg}$ Noyes pellets) on each reward presentation. The other two groups received the same training with high reward (6 pellets) on each presentation. The programming equipment limited reward presentation to one pellet per second. The reward for all groups was presented on a fixed time $30-\mathrm{sec}$ schedule (FT-30 sec). The interreward interval was kept constant for all groups at 30 sec. Each daily session consisted of 30 reward presentations and was approximately $30 \mathrm{~min}$ in length. At the end of each session, the amount of water consumed was measured to the nearest $\mathrm{ml}$. The experiment consisted of two replications with four squads of four animais in each replication. Each squad contained one rat from each of the four treatment groups. The order of running over days was counterbalanced across squads.

On Day 9, one group from each of the high (6) and low (2) reward conditions was shifted to the opposing level of reward. Half the rats that had received six pellets during training now received two pellets, Group 6-2. Half the rats that had received two pellets now received six, Group 2-6. The remainder of the animals were maintained on their original level of reward, either two pellets (Group 2-2), or six pellets (Group 6-6). Postshift testing was continued until Day 13 for a total of five days.

\section{Results}

By Day 8 , all groups showed polydipsic behavior. As can be seen in Figure 1, both high reward (Groups 6-6 and 6-2) and low reward groups (Groups 2-2 and 2-6) showed an increase in water intake over the eight days of training. A 4 by 8 analysis of variance revealed this increase to be reliable over days $[F(7 / 196)=29.25$, $\mathrm{p}<.001$ ). No significant groups effect or Group by Days interaction was obtained [Fgroups $(3 / 28)<1$, FGroup by Days $(21 / 196)=1.31, \mathrm{p}>.05]$. This indicates that no difference in the acquisition of polydipsia was obtained among the four groups. Comparison of the groups' water intake on the control day (Day C) to that on Day 8 showed all groups to be polydipsic $(\mathrm{p}<.05)$.

The main experimental results are presented in the postshift test section of Figure 1. All groups still showed an increase in water intake over the days of testing $[F(4 / 112)=10.61, p<.01]$. However, Group 6-2, which experienced the frustrative downward shift in reward, showed a higher level of water intake throughout testing than its control group (Group 2-2), which was maintained on the lower level of reward $[F(1 / 14)=$ $7.12, \mathrm{p}<.025]$. Group 2-6, which received the upward shift in reward, did not differ from Group 6-6, the high reward control group $[F(1 / 14)<1, p>.05]$.

\section{Discussion}

The present results support the hypothesis that frustration does, at least in part, mediate the production of SIP. The group of animals exposed to the frustrative downward shift in reward showed an increase in water intake relative to its low reward control group. A downward shift in reward produces primary frustration (cf. Ison, Glass, \& Daly, 1969; Rosellini \& Terris, 1975; 
Amsel, 1972). This primary frustration is seen as energizing the next occurring response, which in the present context is drinking. Thus, the increase in water intake in Group 6.2 was expected.

On the basis of previous findings (Falk, 1969) we had expected that the 2-pellet groups would show higher levels of water intake than the 6-pellet groups on the FTFT-30 sec schedule. Falk's rats which received one pellet drank more than rats receiving two pellets on an FT-60 sec schedule. However, a more careful search of the literature revealed results (Bono, 1973; Couch, 1974) which are in agreement with the present findings. These results indicate that increasing meal size does enhance SIP if, as in the present experiment, the number of reinforced periods per session is kept constant for all groups. (In Falk's study the rats in the 1-pellet group also received twice as many reinforced periods as the rats in the 2-pellet group.)

Several of the current hypotheses of SIP do not appear capable of accounting for the findings of the present experiment. Lotter, Woods, and Vasselli (1973) have explained the SIP phenomenon in terms of the artifact of animals taking a consistent amount of water after each meal. Large quantities of water are consumed in the SIP design because the animals are forced to take more than the usual number of meals. However, in the present experiment, all groups were given an equal number of meals, yet the down-shifted group drank significantly more water than a group receiving the same number of meals. Another explanation of SIP has been proposed by Falk (1969). He has pointed out that the amount of water consumed on a polydipsia-producing schedule is inversely proportional to the rate at which animals receive pellets. Therefore, animals which receive a large number of pellets would be expected to drink less than animals receiving only a few pellets. This formulation also fails to explain the present findings. Group 6-2 drank more than Group 2-2, even though both groups were receiving pellets at the same rate during the postshift test.

\section{EXPERIMENT II}

This experiment was undertaken as a further test of the frustration hypothesis of SIP. The strategy was to train rats to tolerate frustration and then test for SIP. A partial reinforcement procedure in a runway was used to establish frustration tolerance. This procedure is held to condition anticipatory frustration stimuli $\left(s_{f}\right)$ to a goal approach response (Amsel, 1971). If, as Experiment I suggests, SIP is mediated by the energizing effects of primary frustration, then rats for which $\mathrm{s}_{\mathrm{f}}$ has been conditioned to goal approach should persist in orienting to the foodcup in the operant chamber and thereby show lower levels of water intake during SIP than a control group not exposed to partial reinforcement.

\section{Method}

Subjects. Ten male Holtzman rats, $320-360 \mathrm{~g}$ in weight, were used in this experiment. They were housed in individual cages and had continuous access to water. Prior to the start of the experiment, all rats were reduced to $80 \%$ of their free feeding weight. Water was continuously available in the home cage during all phases of the experiment.

Apparatus. A straight alley runway and five operant chambers were used. The runway was $120 \mathrm{~cm}$ long $x 16 \mathrm{~cm}$ wide x $36 \mathrm{~cm}$ high. The floor was constructed of stainless steel bars $4 \mathrm{~mm}$ in diam, spaced $15 \mathrm{~mm}$ apart. A guillotine door separated the startbox from the runway. Two photocells and a touch sensitive foodcup were used in conjunction with digital clocks to measure start, run, and goal latencies. The first photocell was located $6 \mathrm{~cm}$ in front of the startbox door. The second photocell was $55 \mathrm{~cm}$ in front of the first. The foodcup was $25 \mathrm{~cm}$ from the second photocell.

The operant chambers were $24 \mathrm{~cm}$ long, $22 \mathrm{~cm}$ high, and $22 \mathrm{~cm}$ wide. Two walls were constructed of aluminum and the other two and the ceiling of clear Plexiglas. The floor consisted of stainless steel grids. A foodcup was centered on the front wall of each chamber, $5 \mathrm{~cm}$ above the floor. A stainless steel drinking spout protruded $2 \mathrm{~cm}$ into the chamber and was $13 \mathrm{~cm}$ to the right of the foodcup. The chambers were housed in a different room from that which housed the runway. White masking noise was used throughout the experiment.

Procedure. Prior to polydipsia testing, all rats were trained to approach food in the runway. They were given 14 days of runway training consisting of 6 trials per day with an intertrial interval of approximately $10 \mathrm{~min}$. Water was not available in the runway. However, it was always available in the intertrial interval, when the animals were returned to their home cages. Each trial began by placing the rat in the startbox of the runway and raising the startbox door as soon as the animal faced in the direction of the goalbox. On each trial, the total time from raising the startbox door to touching the foodcup was recorded.

Partial reinforcement training. On Days 1 and 2 of the experiment, all animals received three food-rewarded trials. Differential runway training was started on Day 3, with five rats randomly assigned to the two treatment groups. Group CRF was given continuous reinforcement training during which one 45-mg Noyes food pellet was available on each of the six daily trials. Group PR was trained on a $50 \%$ partial reinforcement schedule during which one pellet was available on only three of the six trials. The presentation of nonreinforced trials was randomly determined. On the reinforced trials, the animals were allowed to remain in the goalbox until the pellet was consumed, approximately $10 \mathrm{sec}$. On nonreinforced trials they were kept in the goalbox for $10 \mathrm{sec}$.

Polydipsia testing. When the PR and CRF groups showed equivalent runway performance, polydipsia testing in the operant chambers was commenced (Day 8) and was always given following runway training. Since only five chambers were available for this phase of the experiment, three rats from one group and two from the other were tested $1 / 2 \mathrm{~h}$ following runway training. The remainder of each group was tested $11 / 2 \mathrm{~h}$ following the runway training. The order of testing was alternated over days so that an animal tested $1 / 2 \mathrm{~h}$ after training on Day 8 was tested $1 \frac{1}{2} \mathrm{~h}$ after training on Day 9, etc. While awaiting polydipsia testing, the animals were kept in their home cages where water was continuously available.

Polydipsia testing consisted of presenting one 45-mg Noyes pellet on an FT-60 sec schedule. Each testing session was terminated after the delivery of 60 pellets, and the amount of water consumed was measured to the nearest $\mathrm{ml}$. Three days following the end of polydipsia testing (Day 19), all animals were given $1 \mathrm{~h}$ free access to 60 pellets in the operant chamber and water consumption on this control day was measured. 


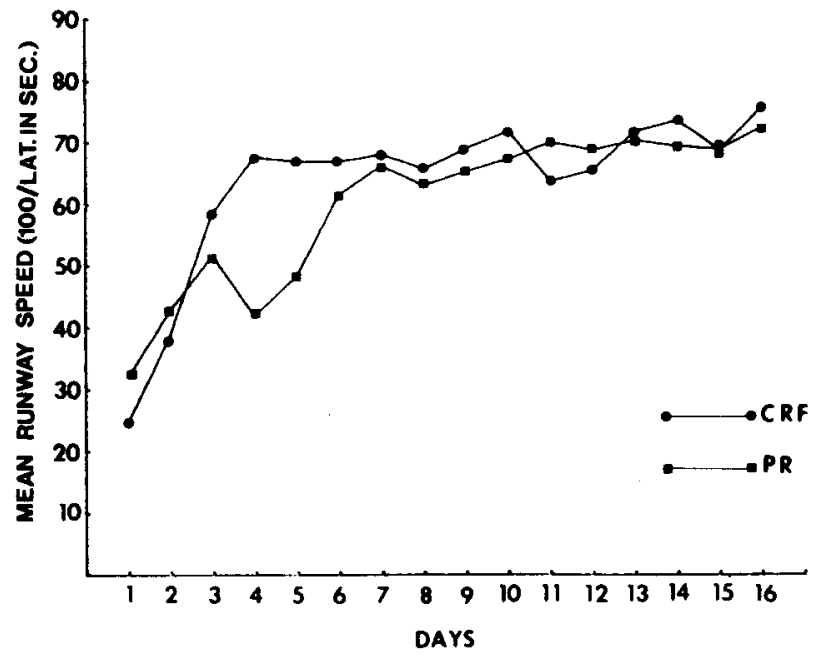

Figure 2. Daily mean total running speed as a function of training groups (PR and CRF) and days of training (Days 1-16)

\section{Results}

Group CRF showed a sharp increase in response speed over days of runway training, while Group PR showed an attenuated increase in speed during the early part of training (Days 3-7). The daily mean total response speed for the two groups is shown in Figure 2. A 2 by 5 analysis of variance showed the two groups to differ in response speed on Days 3-7 of training $[F(1 / 8)=5.42, p<.05]$. However, both groups showed equal runway performance on the subsequent days (8-16) of training. A 2 by 9 analysis of variance showed the groups not to differ in response speed on Days 9-16 [F $(1 / 8)<1]$. One rat from the CRF group was dropped from the experiment due to failure to respond in the runway. The mean of the group was added for this animal's score in all analyses, as suggested by Winer (1971). The adjusted degrees of freedom did not affect the significance levels reported.

The FT-60 sec schedule successfully produced polydipsic behavior. Observation of the animals during this phase of the experiment indicated that bursts of drinking occurred reliably after consumption of the pellets. The mean water intake levels on the control day (Day 19) were $10 \mathrm{ml}$ and $10.6 \mathrm{ml}$ for Groups PR and CRF, respectively. As can be seen in Figure 3, the mean polydipsia levels during testing were $36 \mathrm{ml}$ for the PR group and $46.7 \mathrm{ml}$ for the CRF group. Analysis of the polydipsia testing data using a 2 by 5 analysis of variance revealed a significant days effect $[F(8 / 64)=12.94$, $p<.001]$. This reflected an increase in water intake by both groups over days of testing. However, the groups did show differential amounts of drinking, as indicated by a significant groups effect $[F(1 / 8)=7.26, p<.05]$. The mean water intake over days of testing was $10.7 \mathrm{ml}$ lower for Group PR than for Group CRF. Group CRF demonstrated a higher level of water intake throughout the entire testing period than Group PR. No reliable
Group by Days interaction was obtained [F $(8 / 64<1$, $\mathrm{p}>$.05].

\section{Discussion}

Animals in the PR group ran slower than those in the CRF group at the beginning of partial reinforcement training. However, on Days 8 to 16 the PR group reached asymptotic performance equal to that of the CRF group. This pattern of results is consistent with the findings reported by Wagner (1961) and Robbins (1971), which indicate that animals exposed to partial reinforcement (i.e., frustration) initially exhibit depressed runway speeds but subsequently learn to tolerate the disruptive effects of frustration. This pattern suggests that anticipatory frustration was conditioned to approach to the foodcup for the animals trained on partial reinforcement.

More importantly, the results indicate that the ability to tolerate frustration transferred from the runway to the SIP situation. This was shown by the reduced levels of water intake for the PR group as compared to Group CRF.

During runway training, Group PR persisted in the face of frustration. It is hypothesized that this persistence transferred to the polydipsia testing situation. Observation of the animals during SIP testing showed that the PR rats tended to spend longer periods of time in close proximity to the foodcup during the interpellet interval, whereas Group CRF rats would spend most of this time by the water spout. It is hypothesized that during partial reinforcement training, anticipatory frustration was established as a cue for approach to the foodcup and that the cue properties of anticipatory frustration transferred from the runway to the polydipsia situation. Thus, the PR animals spent more time near the foodcup and predictably showed lower levels of water intake than the CRF animals.

The findings of the present experiments show that by adopting a frustration interpretation of SIP, procedures can be generated which allow the amount of water

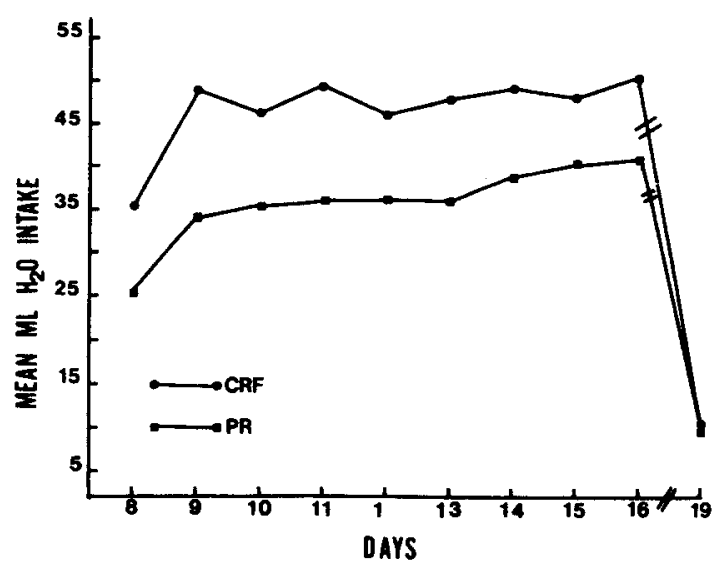

Figure 3. Polydipsia level as a function of training groups (PR and CRF) and days of polydipsia testing (Days 8-16). 
intake on a polydipsia-producing schedule to be manipulated in either an upward or downward direction. In Experiment I, animals which were run under a heightened level of primary frustration showed elevated levels of SIP. In Experiment II, animals were made persistent to cues of anticipatory frustration and the subsequent level of polydipsia was depressed. The frustration-theory explanation of SIP can be applied to a number of other adjunctive behaviors, such as schedule-induced wheel running (Levitsky \& Collier, 1968), air licking (Mendelson \& Chillag, 1970), cellulose shredding (Freed \& Hymowitz, 1969), attack (Flory, 1969), and barpressing (Wayner \& Greenberg, 1973). In all of these instances, the behaviors have been observed under essentially identical experimental conditions to the procedures which produce SIP, with the exception that the water spout has been replaced by a different stimulus object.

\section{REFERENCES}

Amsel, A. The role of frustrative nonreward in noncontinuous reward situations. Psychological Bulletin, 1958, 55, 102-119.

Amsel, A. Frustrative nonreward in partial reinforcement and discrimination learning: Some recent historical and theoreti= cal extensions. Psychological Review, 1962, 69, 306-328.

Amsel, A. Frustration, persistence, and regression. In H. D. Kimmel (Ed.), Experimental psychopathology: Recent research and theory. New York: Academic Press, 1971.

Amsel, A. Behavioral habituation, counterconditioning, and a general theory of persistence. In A. H. Black \& W. F. Prokasy (Eds.), Classical conditioning II. New York: AppletonCentury-Crofts, 1972.

Amsel, A. \& Roussel, J. Motivational properties of frustration. 1. Effect on a running response of the addition of frustration to the motivational complex. Journal of Experimental Psychology, 1952, 43, 363-368.

Bono, N. Schedule-induced polydipsia as a function of the consummation rate. The Psychological Record, 1973, 23, 377-382.

Couch, J. V. Reinforcement magnitude and schedule-induced polydipsia: A reexamination. The Psychological Record, $1974,24,559-562$.

Denny, M. R., \& Ratner, S. C. Comparative psychology: Research in animal behavior. Homewood, Ill.: The Dorsey Press, 1970.

Falk, J. L. Production of polydipsia in normal rats by an intermittent food schedule. Science, 1961, 133, 195-196.
Falk, J. L. Conditions producing psychogenic polydipsia in animals. Annals of the New York Academy of Sciences, $1969,157,569-593$.

Falk, J. $\dot{L}$. The nature and determinants of adjunctive behavior. Physiology and Behavior, 1971, 6, 577-588.

Flory, R. K. Attack behavior as a function of the minimum inter-food interval. Journal of the Experimental Analysis of Behavior, $1969,14,825-828$.

Freed, E. X., \& Hymowitz, N. A fortuitous observation regarding "psychogenic" polydipsia. Psychological Reports, 1969, 24, 224-226.

Ison, J. R., Glass, D. H., \& Daly, H. B. Reward magnitude changes following differential conditioning and partial reinforcement. Journal of Experimental Psychology, 1969 , $81,81-88$.

Kachanoff, R., Leveille, R., McClelland, J. P., \& Wayner, M. J. Schedule-induced polydipsia in humans. Physiology and Behavior, 1973, 11, 395-398.

Kissileff, H. R. Nonhomeostatic controls of drinking. In A. N. Epstein, H. R. Kissileff, \& E. Stellar (Eds.), Neuropsychology of thirst: New findings and advances in concepts. Washington: V. H. Winston \& Sons, 1973

Levitsky, D., \& Collier, G. Schedule-induced wheel running. Physiology and Behavior, 1968,3,571-573.

Lotter, E. C., Woods, S. C., \& Vasselli, J. R. Schedule-induced polydipsia, an artifact. Journal of Comparative and Physiological Psychology, 1973, 83, 478-484.

Mendelson, J., \& Chillag, D. Schedule-induced air licking in rats. Physiology and Behavior, 1970, 5, 535-537.

Palfai, T., Kutscher, C., \& Symons, J. Schedule-induced polydipsia in the mouse. Physiology and Behavior, 1971, 6, 461-462.

Panksepp, J., Toates, F. M., \& Oatley, K. Extinction induced drinking in hungry rats. Animal Behavior, 1972, 20, 461-462.

Robbins, D., Partial reinforcement: A selective review of the alleyway literature since 1960. Psychological Bulletin, 1971, $76,415-431$.

Rosellini, R. A., \& Terris, W. Incentive shift in the rat following training to resist punishment. Learning and Motivation, 1975. in press.

Schuster, C. R., \& Woods, J. H. Schedule induced polydipsia in the monkey. Psychological Reports, 1966, 19, 823-828.

Shanab, M. E., \& Peterson, J. L. Polydipsia in the pigeon. Psychonomic Science, 1969, 15, 51-52.

Wagner, A. R. Effects of amount and percentage of reinforcement and number of acquisition trials on conditioning and extinction. Journal of Experimental Psychology, 1961, 62, 234-242.

Wayner, M. J., \& Greenberg, I. Schedule dependence of schedule induced polydipsia and lever pressing. Physiology and Behavior, 1973, 10, 965-966.

Winex, B. J. Statistical principles in experimental design. New York: McGraw-Hill, 1971.

(Received for publication March 24, 1975.

Revision accepted June $24,1975$. ) 